Organization : Theory and Practice". Among the large-batch and mass-production firms a relation was observed between conformity with the 'rules' of management and business success, and, within this limited range of production systems, observance of these 'rules' appears to increase administrative efficiency. Elsewhere, however, it appears that new 'rules' are needed and an alternative kind of organizational structure might be more appropriate. This does not invalidate management theory, which contains important and valuable information and ideas, but its limitations must be recognized and its principles subjected to critical analysis. Broadly, the survey brings out the way in which management organization varies according to the technical demands of the manufacturing process. The character of the basic functions of management, their chronological sequence, their integration and their relative importance to the success and survival of the business, all depend on the system of techniques in the particular firm, and they differ mainly between unit, mass and process production, all of which have different priorities.

Accordingly, a 'cause and effect' relation can be traced between a system of production and its organizational pattern, and, as a result, the probable organizational requirements predicted. The booklet emphasizes the danger in the tendency to teach the principles of administration as if they were scientific laws, when they are really little more than administrative expedients. Management studies can, so far, identify symptoms and remedies, but many more descriptive accounts, like that given in this booklet, of the circumstances in which different administrative expedients have proved successful are required to supplant traditional teaching. It is also concluded that technical changes not associated with changes in either objectives or the production system are unlikely to create much disturbance in the organizational pattern. Where, however, such changes are likely to create new 'situational demands', these could be foreseen by a systematic analysis of the new technology.

\title{
HUMAN RELATIONS IN INDUSTRY
}

$I^{\mathrm{N}}$ $\mathrm{N}$ its final report*, the Joint Committee on Human Relations in Industry, 1954-57, reviewing research projects approved since its first report, records that a practical inquiry into the effects of work study on human relations and organization at every level in the firm is well advanced, and further support was recommended for a team from the University of Manchester to continue to work on a large scale for three years on social factors affecting norms of production in British factories. An investigation into incentives for management had to be abandoned because suitable staff could not be found, but the National Institute of Industrial Psychology has been asked to undertake case-studies of the way in which individual firms have tackled the problem of foremanship.

Research in the field of industrial communication has been extended to eover the communication of technical information to firms from outside sources, and the inquiry conducted by the Oxford Institute of Statistics into factors affecting productivity has been extended to social factors in seeking for an explanation-psychological and social, as well as economic-of differences in productivity between and within the firms studied. Research into the community aspects of technological change in South Wales has centred around the exceptionally modern and highly mechanized Margam steel plant and, at Cardiff, on the impact made on the structure and procedure of the trades unions by the new steel plant.

The Acton Society Trust is making a case-study of the introduction of a management-development programme, and a study of educational provision and the needs of industry by the Tavistock Institute of Human Relations is also being supported. Work at the London School of Economics on the employment of women in industry was extended for two years, and some exploratory work was undertaken at the University of Edinburgh into the employment of older workers in industry.

- Department of Scientifle and Industrial Research. Final Report of the Joint Committee on Human Relations in Industry 1954-57 and Report of the Joint Committee on Individual Efficiency in Industry 1953-57. Pp. vi +44. (London: H.M. Stationery Office, 1958.) 8s. net.
Projects sponsored by the Joint Committee on Individual Efficiency in Industry fall into four groups. Those concerned with factors affecting equipment design and working conditions include two studies, by the Medical Research Council's Applied Psychology Research Unit at Cambridge, of manual controls of machine tools and of visual fatigue. The former greatly increased the speed of machine-working and reduced the number of errors and learning-time. Other studies were concerned with the design and layout of control points in steelworks, with special reference to crane-cabs, with machine controls in relation to equipment used in the boot and shoe industry and with the response to work in high temperatures in relation to age. Projects concerned with industrial engineering techniques embrace those of the nature and acquisition of industrial skills by the Department of Engineering Production at the University of Birmingham and of work-study rating, rest and fatigue allowances by the Department of Aircraft Economics at the College of Aeronautics, Cranfield.

Studies of problems of training include those by the National Institute of Industrial Psychology of methods of training in industrial skills; of conditions influencing the rate of learning of paced and unpaced motor tasks by the University of Oxford Institute of Experimental Psychology; of the methods used by the best operatives and their application to the training and re-training of operatives by the British Boot, Shoe and Allied Trades Research Association; and of reading efficiency by the Department of Commerce and Professional Studies at the North-Western Polytechnic, London.

Among the group of miscellaneous projects may be mentioned one on the effect of knowledge of results on production made by the Medical Research Council's Applied Psychology Research Unit ; an investigation of indices commonly regarded as indicating the adjustment of the individual to his job; and a study of automation in relation to skill and the design of machines by the Department of Psychology, University of Cambridge. 